\title{
EXPERIMENTAL AND NUMERICAL INVESTIGATIONS OF HEATING IN A BUS CABIN UNDER TRANSIENT STATE CONDITIONS
}

\author{
ÖZGÜR EKICI ${ }^{1} \&$ GÖKHAN GÜNEY ${ }^{2}$ \\ ${ }^{1}$ Department of Mechanical Engineering, Hacettepe University, Turkey \\ ${ }^{2}$ MAN Turkey A.Ş., Turkey
}

\begin{abstract}
This study carries out an experimental and numerical work in order to investigate the air flow and temperature fields inside a coach bus cabin. In addition to a real-world experiment, an existing bus heating system has been investigated computationally using a three-dimensional model consisting of one seating row with periodical and symmetrical boundary conditions (BCs) as required. The seats, without including passengers as has been the case in the experiments, are created with adiabatic BCs. The developed computational fluid dynamics (CFD) model is used in a transient analysis of heating by employing the "Boussinesq Approximation" for buoyancy-induced effects and incorporating the experimentally obtained BCs into the system. The model validation is performed by comparing model results against experimentally obtained ones for three regions, corresponding to head, knee, and foot level of passengers. The difference between the measured and the calculated temperatures is found to be less than around $3^{\circ} \mathrm{C}$ for the head and foot level, while it is $5^{\circ} \mathrm{C}$ for the knee level of the passenger for the transient heating simulation.
\end{abstract}

Keywords: CFD, experimental, thermal comfort, modelling, heating, bus cabin.

\section{INTRODUCTION}

Heating, ventilation and air conditioning (HVAC) of coaches are generally provided by an air conditioner unit which operates in a closed-circuit cooling system. A standard HVAC unit consists of a compressor, evaporator, condenser and an expansion valve. The conditioned air is distributed inside the cabin via 2 main perforated air ducts located above the passenger seats along the cabin. There are also two main convector lines available, at the two bottom sides in the cabin, used for heating purposes. These systems are controlled by the driver using control switches located on the instrument panel in order to set the cabin air temperature to the desired level. However, air temperature varies along the cabin due to changing conditions along the fuselage such as number of passengers, conditioned air demand and even as a result of proximity to the main heat source: the engine. Because of these varying conditions, it is important to maintain a nearly homogeneous temperature distribution inside the cabin for passengers' comfort.

The assessment of the thermal comfort inside vehicle cabins has been researched immensely for a long time. In literature, a number of studies dealing with improvement of air quality and thermal comfort are available. Zhu et al. [1] carried out numerical and experimental investigation for public transportation buses, a computational model was developed first then experimentally verified. The obtained results showed that an increased risk for airborne transmitted diseases in public transportation system due to a lack of sufficient ventilation. Petrone et al. [2] studied on passengers' comfort for thermal and fluid-dynamical optimization in a touring bus cabin. Air terminal layout and configuration of inlet section for ventilation air were optimized. Combination of a standard ceiling system with a displacement scheme for heating air inlet represented the best compromise guaranteeing thermal comfort for passengers. In a different study Zítek et al. [3] proposed a new personalized and humidified air supply, the system was analyzed with Fluent CFD 
program and validated by laboratory experiments. The ASHRAE Standard 55 [4] identifies thermal comfort as "that state of mind which expresses satisfaction with the thermal environment". Ružić [5] proposed improvement of thermal comfort in a passenger car by localized air distribution. The paper ensures an overview of local microclimate parameters which HVAC system should achieve in a vehicle cabin in warm ambient, regarding thermal sensitivity of individual parts of human body obtained from empirical data. Zhang et al. [6] used the CFD method to simulate three-dimensional temperature distributions and flow field in a car compartment with and without passengers. They validated their numerical model by comparing its results against the experimental data. The validated numerical model was then used to investigate the influence of different factors on the thermal comfort and the energy consumption.

In this manuscript, the main focus is on heating analysis of the coach and verification of the analysis with test results. The objective of this study is to investigate the air velocity and the temperature distribution inside a coach bus cabin using a developed computational model and an experimental study.

\section{METHODOLOGY AND EXPERIMENTAL STUDIES}

First, the computational methodology then the experimental setup is explained in this section. In order to reach our objectives, a representative 3D cabin design of the coach with air inlets and outlets are taken into account. Then, the meshing and mesh assessment phases are proceeded. The next step is to set up the solver and run the simulations to receive the computational results. As another dimension of the study, experiments, which include temperature measurements alongside the cabin while the coach operates in field, are conducted. After receiving all the results, a comparison of the simulation and experimental test results is made.

\subsection{Theory}

The vast majority of real-world fluid flows are characterized as turbulent since they have irregular motion in the domain of interest. In scope of this thesis study, the RNG k- $\varepsilon$ model is employed similar to the studies in the literature [7]-[9], to simulate the turbulent airflow occurring inside the cabin.

\subsubsection{Governing equations}

The governing equations in fluid dynamics are the Reynolds Averaged Navier-Stokes equations. When the velocity is decomposed into fluctuating and mean parts as shown in eqn (1),

$$
u_{i}=U_{i}+u_{i}^{\prime}
$$

where $U_{i}$ is the mean and $u_{i}^{\prime}$ the fluctuating part. Instantaneous Reynolds-averaged Navier-Stokes eqns can be written as shown in eqns (2), (3) and (4):

$$
\begin{gathered}
\frac{\partial U_{i}}{\partial x_{i}}=0 \\
\rho \frac{\partial U_{i}}{\partial t}+\rho U_{j} \frac{\partial U_{i}}{\partial x_{j}}=-\frac{\partial P}{\partial x_{i}}+\frac{\partial}{\partial x_{j}}\left[\mu\left(\frac{\partial u_{i}}{\partial x_{j}}-\overline{u_{i} u_{j}}\right)\right],
\end{gathered}
$$




$$
\rho \frac{\partial T}{\partial t}+\rho U_{j} \frac{\partial T}{\partial x_{j}}=\frac{\partial}{c_{p} \partial x_{j}}\left(k \frac{\partial T}{\partial x_{j}}\right)-\frac{\partial \overline{u_{i} T}}{\partial x_{j}},
$$

where $\rho$ is the density, $\mu$ the dynamic viscosity, $u$ the velocity, $P$ the pressure, $T$ the temperature, $t$ the time, $x_{i}$ the $x, y, z$ position tensor, $c_{p}$ the specific heat capacity, $k$ the thermal conductivity and $\overline{u_{i} u_{j}}$ the Reynolds stress tensor.

Temperature differences in the flow domain will cause a density variation and as a result buoyancy forces need to be taken into account. Buoyancy induced flows are driven owing to density changes in the fluid domain. The density variations are negligible based on the Boussinesq approximation; it is basically assumed that, the flow is incompressible, i.e., density is constant in all terms except the body force. This assumption is the fundamental of the Boussinesq approximation. Then the body force term is written, eqn (5), as a function of gravitational acceleration, temperature difference and a material property called the thermal expansion coefficient, $\beta$.

$$
F=\left(\rho-\rho_{0}\right) g \approx-\rho_{0} \beta\left(T-T_{0}\right) g .
$$

Substituting eqn (4) into the momentum equation gives:

$$
\frac{D u}{D t}=-\frac{1}{\rho_{0}} \nabla p-g \beta\left(T-T_{0}\right)+v \nabla^{2} u .
$$

Note that the laminar form is used for clarity in eqn (6).

\section{$2.23 \mathrm{D}$ cabin geometry}

The detailed cabin geometry of Lion's Coach R08, test vehicle is unnecessarily complex to run a computational analysis for the scope of this study. First of all, many details, which are important in a structural analysis such as fasteners and connectors, are not required in a flow analysis because they will have no effect on the bulk flow properties to be investigated.

An isometric view of the simplified geometry for the computational domain is presented in Fig. 1. The model is created using CATIA V5-6R2014 and imported into ANSYS R16.2. The simplified cabin consists of subtracted seats as has been generally implemented in similar studies [10], [11]. In addition, 2 air outlet grids, a window and side panel as well as 2 air inlet locations and convector are considered as shown in the Fig. 1.

One of the air inlet locations includes 3 rectangular air nozzles and blows air through the lateral side while the other one has 2 circular air nozzles and supplies air in the gravitational direction (-z direction in this case) basis on ZY plane as specified in Fig. 1 schematically. To simplify the model and to reflect the behavior of the overall cabin, periodicity BCs are assumed in front and back of the model.

\subsection{Meshing and BCs}

In meshing, the number of elements, the quality of elements, elements close to the physical boundaries, face sizing on inlets and outlets and curvatures are all important and needed to be considered carefully. In the base mesh model, there are $101 \mathrm{k}$ nodes and around $430 \mathrm{k}$ cells. For the quality of the meshing, skewness and orthogonal quality are to be evaluated as well. At the end of the meshing, 0.25 and 0.80 of skewness values in average and maximum rates are observed respectively. These values indicate that the current mesh structure is sufficient to be employed. 


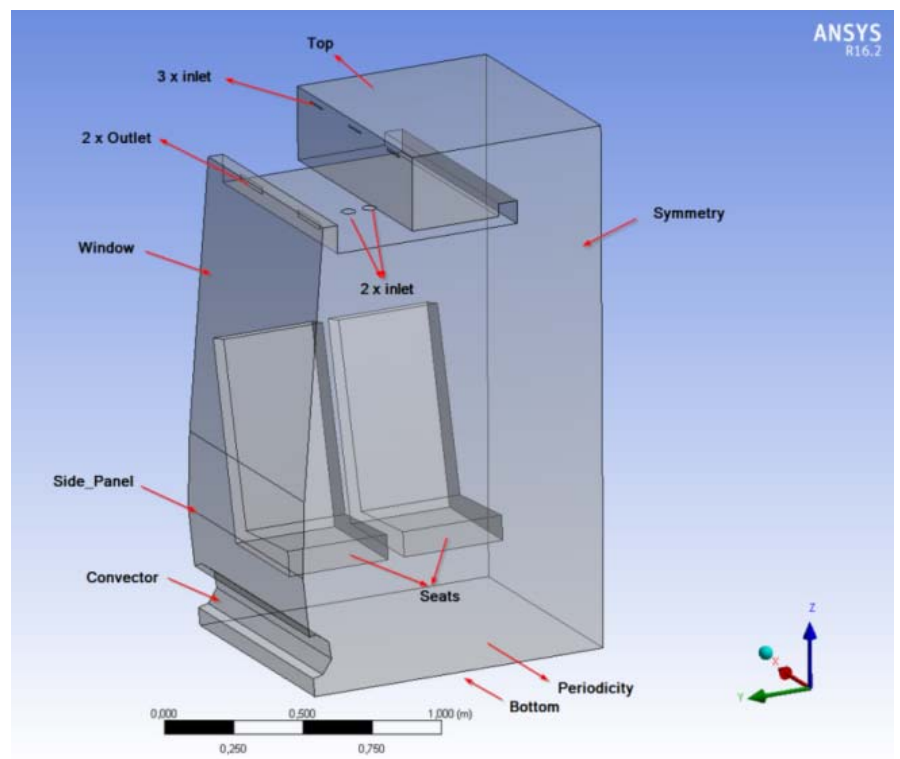

Figure 1: Isometric view of the cabin.

All BCs are summarized in Table 1. Note that at the window boundary, convective heat transfer is used and the coefficient is determined according to eqn (7) which is commonly used in literature [12]:

$$
N u=\frac{h L}{k}=0.037 \operatorname{Re}_{x}^{4 / 5} \operatorname{Pr}^{1 / 3} \quad\left\{0.6 \leq \operatorname{Pr} \leq 60 \quad 5 \times 10^{5} \leq \operatorname{Re}_{L} \leq 10^{7}\right\}
$$

Table 1: BCs of the surfaces in the heating analysis.

\begin{tabular}{|l|l|l|l|l|l|l|}
\hline BC & Type & Material & $\begin{array}{l}\text { Shell } \\
\text { conduction }\end{array}$ & $\begin{array}{l}\text { Heat transfer } \\
\text { coeff. } \\
\left(\mathbf{W} / \mathbf{m}^{2} \mathbf{K}\right)\end{array}$ & $\begin{array}{l}\text { Free stream } \\
\text { temp. } \\
\left({ }^{\mathbf{}} \mathbf{C}\right)\end{array}$ & $\begin{array}{l}\text { Wall } \\
\text { thickness } \\
(\mathbf{m})\end{array}$ \\
\hline Airduct & $\begin{array}{l}\text { Wall } \\
\text { (constant temp.) }\end{array}$ & Aluminum & Yes & 0 & 41 & 0.005 \\
\hline Bottom & $\begin{array}{l}\text { Wall } \\
\text { (constant temp.) }\end{array}$ & Aluminum & Yes & 0 & 5 & 0.005 \\
\hline Convector & $\begin{array}{l}\text { Wall } \\
\text { (constant temp.) }\end{array}$ & Aluminum & Yes & 0 & 54 & 0.005 \\
\hline Seat aisle & $\begin{array}{l}\text { Wall } \\
\text { (adiabatic) }\end{array}$ & Aluminum & No & 0 & - & 0 \\
\hline Seat window & $\begin{array}{l}\text { Wall } \\
\text { (adiabatic) }\end{array}$ & Aluminum & No & 0 & - & 0 \\
\hline Side panel & $\begin{array}{l}\text { Wall } \\
\text { (constant temp.) }\end{array}$ & Aluminum & Yes & 0 & 5 & 0.005 \\
\hline Symmetry & Symmetry & Aluminum & No & 0 & - & 0 \\
\hline Top & $\begin{array}{l}\text { Wall } \\
\text { (constant temp.) }\end{array}$ & Aluminum & Yes & 0 & 5 & 0.005 \\
\hline Window & Wall (convective) $)$ & Glass & Yes & 77.27 & 5 & 0.005 \\
\hline
\end{tabular}


The materials' thermal properties, hydraulic diameter values on the inlet and outlet boundaries as well as turbulent intensity used in the analysis are specified in Table 2 and Table 3 , respectively.

As presented with red circles in Fig. 2, the refinement with face sizing method applied by assigning elements' sizes as $3 \mathrm{~mm}$ for the outlet, $2 \mathrm{~mm}$ for the inlet 1 and $1 \mathrm{~mm}$ for the inlet 2 boundaries in order to resolve the flow characteristics precisely. These element sizes are specified proportional according to the dimensions of the holes. Besides, next to the physical boundaries, 8 inflation layers with 1.1 growth rates and $1 \mathrm{~mm}$ of the first layer thickness are implemented and smooth transition option is used to capture the key variables such as temperature and velocity gradients correctly in the vicinity of the seats and the solid walls.

Tetrahedral grid structure has been created for the air flow volume in order to capture temperature and velocity gradients in detail. In addition, the prismatic inflation layers have been applied around the solid walls, namely, seats, convector, side panel and window, which are pre-determined [13], [14] and given in Fig. 2 for window, side panel and convector. They are used for getting the solutions with higher accuracy satisfying y-plus $<5$.

Table 2: Material data used throughout the study.

\begin{tabular}{|l|l|l|l|}
\hline Material & $\begin{array}{l}\text { Density } \\
\left(\mathbf{k g} / \mathbf{m}^{\mathbf{3}}\right)\end{array}$ & $\begin{array}{l}\mathbf{C}_{\mathbf{p}} \\
(\mathbf{J} / \mathbf{k g K})\end{array}$ & $\begin{array}{l}\text { Thermal conductivity } \\
(\mathbf{W m K})\end{array}$ \\
\hline Aluminum & 2719 & 871 & 202.4 \\
\hline Glass & 2700 & 840 & 0.78 \\
\hline
\end{tabular}

Table 3: Inlet and outlet parameters.

\begin{tabular}{|l|l|l|l|l|l|}
\hline BC & Type & $\begin{array}{l}\text { Velocity } \\
(\mathbf{m} / \mathbf{s})\end{array}$ & $\begin{array}{l}\text { Temperature } \\
\left({ }^{\circ} \mathbf{C}\right)\end{array}$ & $\begin{array}{l}\text { Hydraulic } \\
\text { diameter } \\
(\mathbf{m})\end{array}$ & $\begin{array}{l}\text { Turbulent } \\
\text { intensity } \\
(\mathbf{\%})\end{array}$ \\
\hline Inlet 1 & Velocity inlet & 2.1 & $42 /$ UDF & 0.052 & 5 \\
\hline Inlet 2 & Velocity inlet & 1.79 & $42 /$ UD & 0.0097 & 5 \\
\hline Outlet & $\begin{array}{l}\text { Pressure } \\
\text { outlet }\end{array}$ & - & $5 /$ UDF & 0.0149 & 5 \\
\hline
\end{tabular}

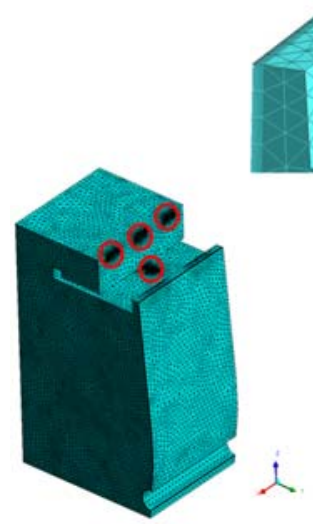

(a)

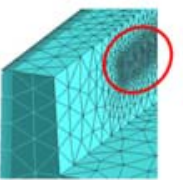

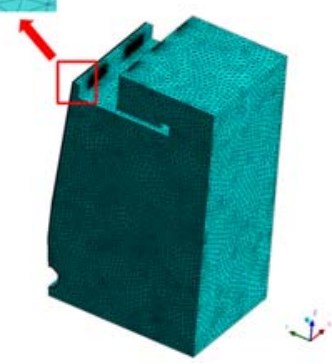

(b)

Figure 2: Face sizing on (a) inlet and (b) outlet boundaries and inflations. 


\subsection{Solver settings}

ANSYS Fluent software solves continuity, momentum and energy equations numerically with a finite volume method. In numerical solution, second-order upwind discretization method is used for convective terms and the well-known SIMPLE algorithm is employed to couple the pressure and velocity. The transient flow characteristics are set as incompressible and turbulent. The humidity and radiation heat transfer effects are neglected. As presented in Table 1, no slip conditions are specified for all surfaces with adiabatic BCs for the seats and constant temperature BCs for the other solid walls except windows, which have convection $\mathrm{BCs}$ outside. As a solution strategy, solver is set to a first order scheme initially. Afterwards, the Boussinesq approximation with second order scheme is employed to get the final results.

\subsection{Experimental study}

BCs and other data for validating the developed CFD method are collected during an experiment. The bus engine is kept in idle condition and there are no people inside. During the measurements, all of the windows and doors are fully closed as specified in the similar experiment conducted by $\mathrm{Zhu}$ et al. [1]. To investigate the heating performance, vehicle is driven along a pre-determined path in the lowest operating temperatures in field to simulate the extreme-low outer temperatures. Temperature inside the cabin is measured in four main areas: the cabin sensor at the middle of the cabin, the head and the knee as well as the foot of the passenger [6]. During this experiment, winter test preparations are completed before the test. In this preparation, the first aim is to keep fresh air inlet and air outlet under control and proportional with each other to prevent pressure accumulation inside the cabin. In order to provide an airtight passenger compartment smoke test is conducted by managing all HVAC devices with $100 \%$ fresh air to generate maximum pressure inside the passenger compartment.

Secondly, air blowing and suctioning test is realized. Main purpose is to determine whether the fresh air intake and air return mechanisms work properly and sufficiently. The final milestone of the preparation is the determination of measurement points. The best locations are chosen by an operator who has the most experience in this sort of test. In the experiments, the air velocities, on the nozzles, which are named inlet 1 and inlet 2, and located on the vehicle's air channel are measured using an anemometer, Testo 435-4. In addition, the temperature values are measured with K-type thermocouples and recorded by a computer with mLap (Data acquisition and Test rig control) and mGraph (Data Analysis) through QIC Thermo 16 system.

\section{RESULTS}

In parallel to the verification and qualitative validation of computational model's results by conducting grid and time-step studies, examining fundamental flow physics, experimental test results are obtained. Note that, verification and validation studies of CFD model are not presented due to length limitations. The transient test results are reported in Fig. 3 for various locations in the cabin for 85 min.

During the heating tests, the empty vehicle is driven at an outer temperature of $5^{\circ} \mathrm{C}$ to be able to observe the system performance under mild weather conditions, where the relative humidity is $0 \%$ and the wind speed is $80 \mathrm{~km} / \mathrm{h}$.

Air temperature comparison results are shown in Fig. 4 for head level of the aisle passenger. It is observed that the CFD simulation results and the experimental data have the same trend and the temperature differences are ignorable particularly after $50 \mathrm{~min}$ of the total heating period. 


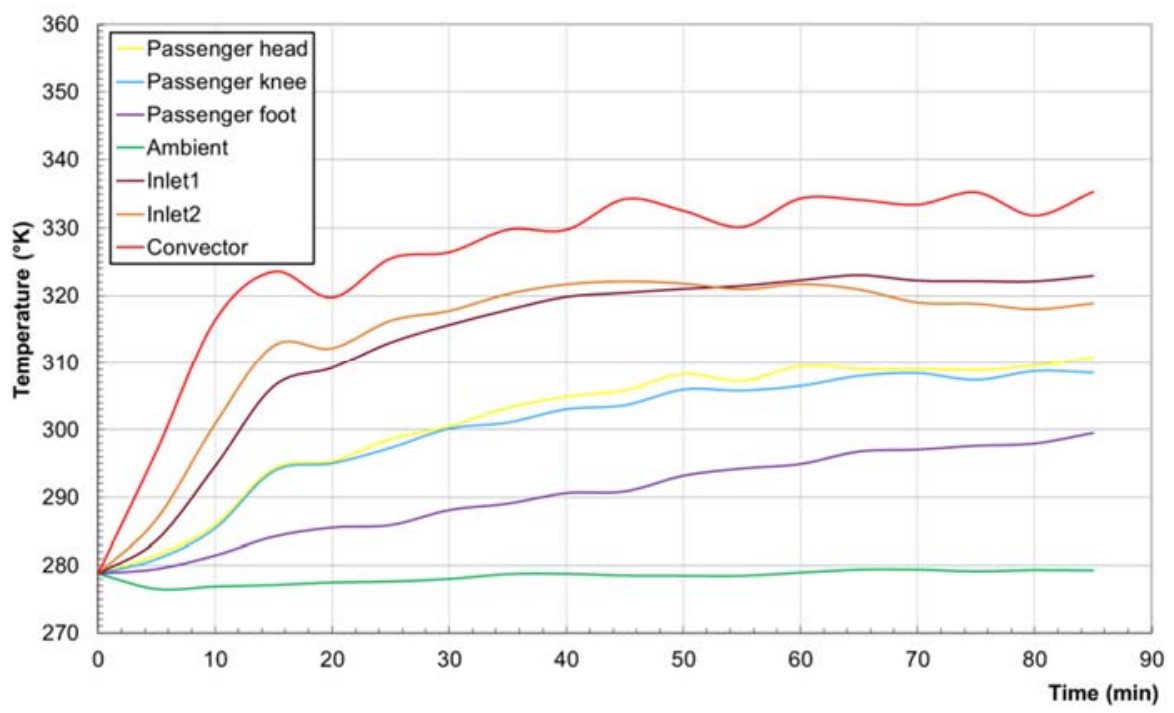

Figure 3: Transient heating test results started at $5^{\circ} \mathrm{C}$ ambient temperature.

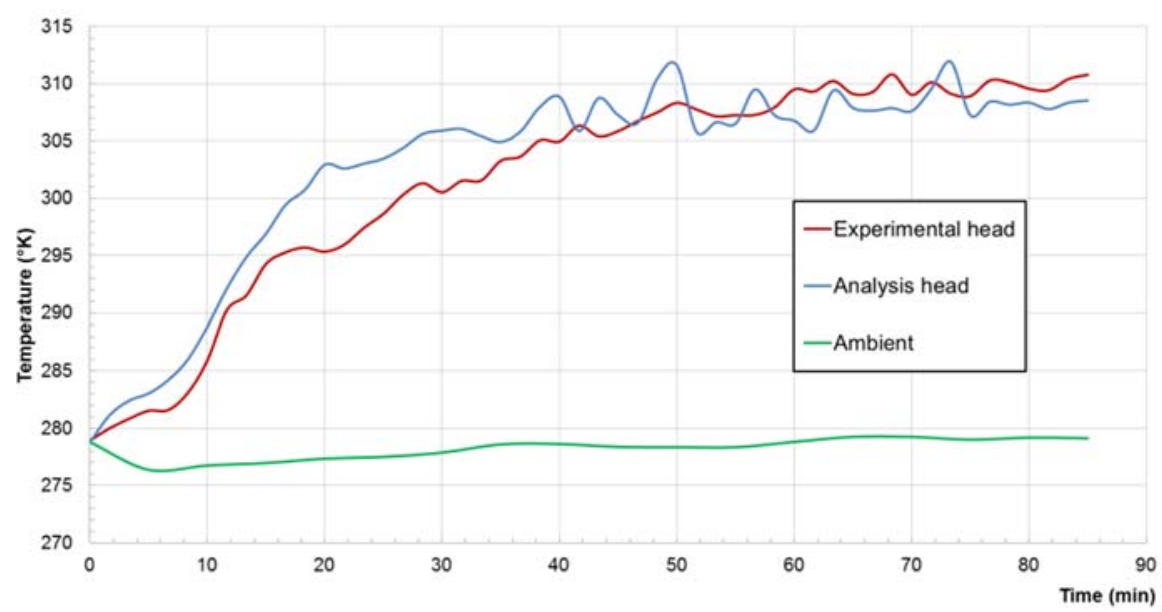

Figure 4: Comparison of simulation model results and experimental results at the head level of the aisle passenger.

Results presented in Fig. 5 are generally in good agreement with each other, while the experimental results look more stable or steady-like compared to the predicted results which could be due to location of measurement point. The highest temperatures are observed at the end of the heating process for both cases as expected. Because on this time fluid flow, especially in the experimental study, reaches the saturation points where the temperature values do not change significantly. 


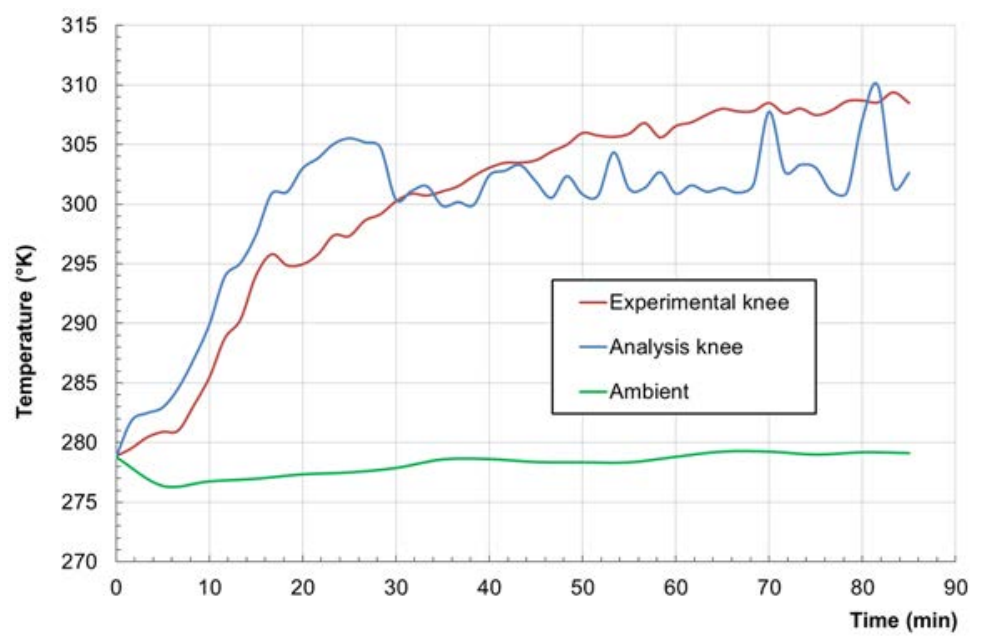

Figure 5: Comparison of simulation model results and experimental results at the knee level of the aisle passenger.

For the foot level, simulation results stabilize earlier than the head level as seen in Fig. 6. It is likely because of poor air flow in the vicinity of the foot level of the passenger. Besides, the gap between the simulation and test results starting around $10 \mathrm{~min}$. to $40 \mathrm{~min}$. is much noticeable at the foot level of the passenger. It is believed that both discrepancies observed here are essentially as a result of the physical distinction between the simulation model and the real vehicle geometry

The air temperature values, on the passenger head level at the parallel section to the floor, are shown in Fig. 7. As expected, the region closer to the window side gives relatively and locally lower temperature values than the temperature values of the bulk region of the fluid flow domain as a result of high thermal losses by convection heat transfer occurred on the outside of the window glass.

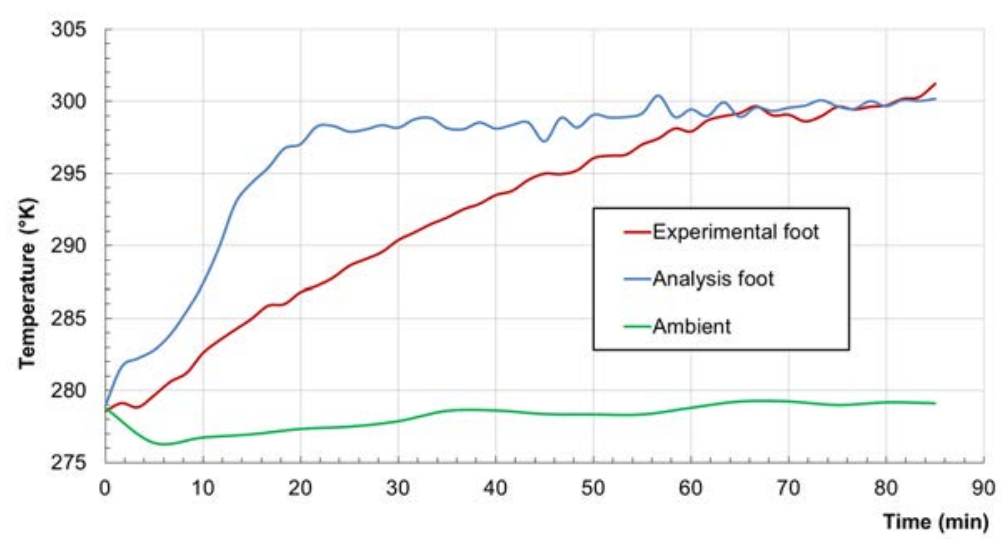

Figure 6: Comparison of simulation model results and experimental results at the foot level of the aisle passenger. 


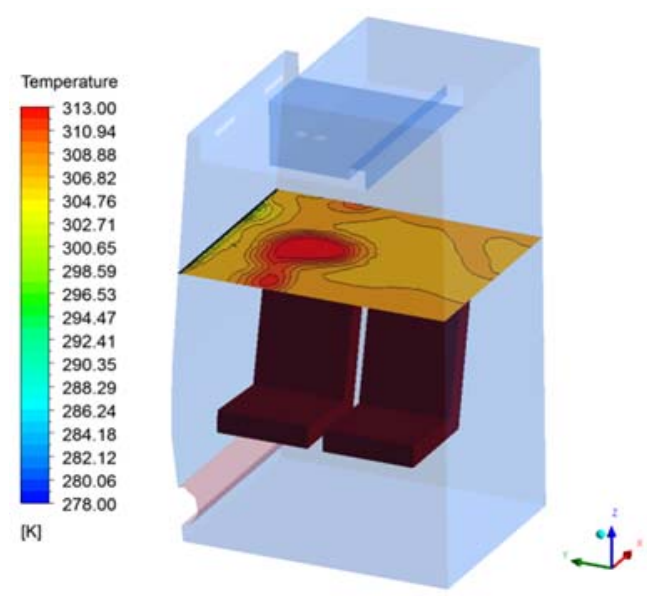

Figure 7: Transient heating simulation results at $5^{\circ} \mathrm{C}$ ambient temperature on passenger head level parallel to the floor.

As it can be seen in Fig. 8, the air flow patterns are not symmetrical and the passenger on the window side is exposed to more air flow compared to the passenger on the aisle side as expected, because blower air outlet directions are chosen normal to the structure plane in this study. In general, the large recirculation zones were observed along the air blowing directions and in the proximity of the passenger seats which play role as an obstacle against the air flow. Moreover, smaller recirculation regions were also predicted on the area under the window seat because of the free space between the convector and the seat as well as on the region closer to floor of the passenger cabin.

In scope of this study, a small case study has been carried out. It investigates the effects of different turbulence models on the simulated results. The simulation results are slightly different for each of the turbulence models as indicated in Fig. 9. The RNG k- $\varepsilon$ and standard

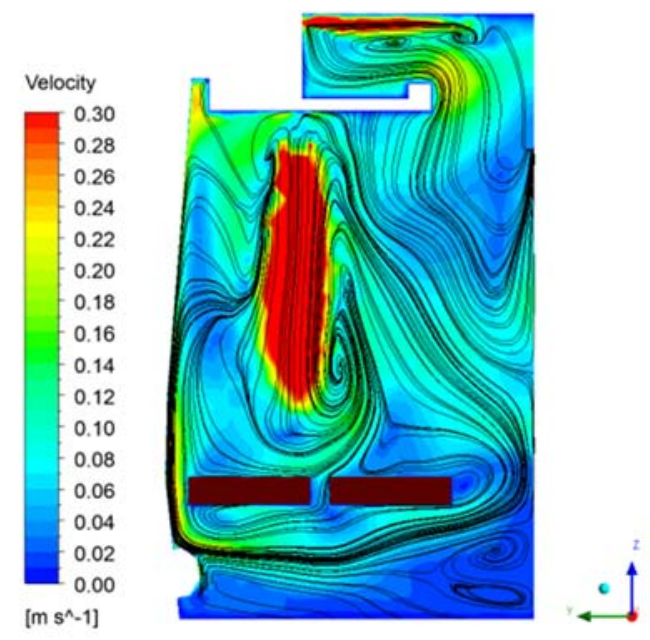

Figure 8: Air velocity contours and streamlines in lateral direction on inlet 1. 


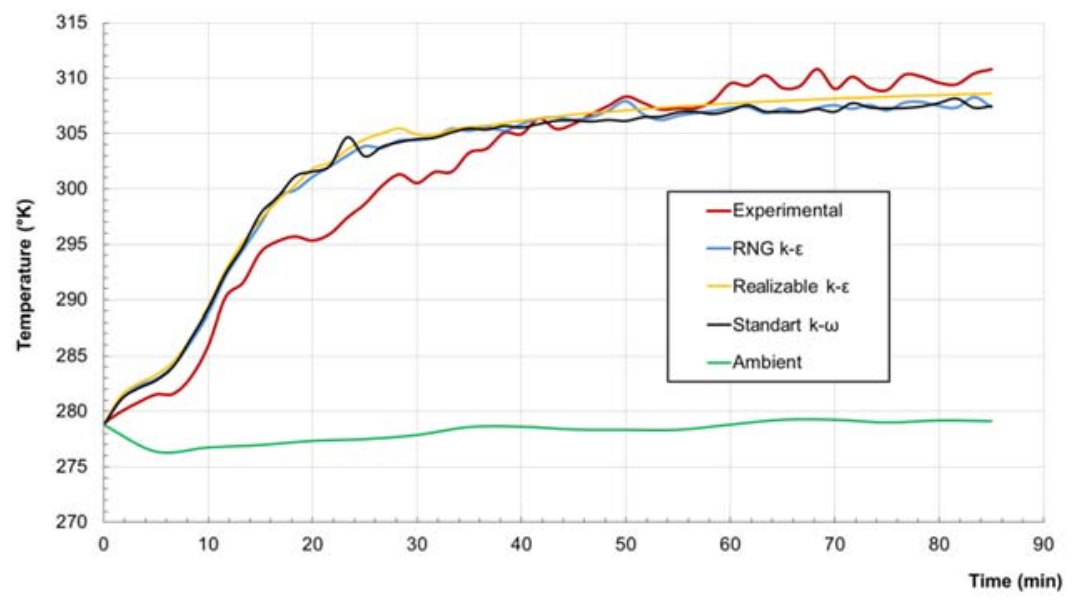

Figure 9: Head-level temperatures for different turbulence models.

$\mathrm{k}-\omega$ turbulence models had the same trend and were so close each other but the difference between the experimental data was reaching till $6^{\circ} \mathrm{C}$ and $3{ }^{\circ} \mathrm{C}$ at the initial time and end of the simulations respectively, while the realizable $\mathrm{k}-\varepsilon$ turbulence model suggested that the closer temperature to the experimental study and more stable flow especially at the last $30 \mathrm{~min}$ of the analysis.

\section{CONCLUSIONS}

In this study, a computational and experimental investigation of temperature distribution inside a coach bus cabin is conducted. A three-dimensional computational model is started to be developed by employing various geometrical and physical simplifications. It is shown that the buoyancy induced flow changes the temperature distribution in the domain significantly. In addition, comparing experimental test results with the obtained computational results show that quantitatively very good predictions have been made despite the simplifications in the model for the heating tests conducted in this study. The major difference between the experimental and computational results is found to be at the initial period of the transient physics and it is most likely because of the physical distinction between the computational model and the real vehicle geometry which includes the other bus components such as windshield, the rear window, driver place's elements and staircases etc. Closer simulation results with less temperature difference to experimental ones can be predicted by modelling the whole bus passenger compartment.

\section{REFERENCES}

[1] Zhu, S., Demokritou, P. \& Spengler, J., Experimental and numerical investigation of micro-environmental conditions in public transportation buses. Building and Environment, 45, pp. 2077-2088, 2010.

[2] Petrone G., Fichera G. \& Scionti M., Thermal and fluid-dynamical optimisation of passengers comfort in a touring bus cabin. Excerpt from the Proceedings of the COMSOL Conference, Hannover, 2008.

[3] Zítek, P., Vyhlídal, T., Simeunovic, G., Nováková, L. \& Cízek, J., Novel personalized and humidified air supply for airliner passengers. Building and Environment, 45, pp. 2345-2353, 2010. 
[4] ASHRAE American Society of Heating Refrigerating and Air Conditioning Engineers Standard 55, Thermal Environmental Conditions for Human Occupancy: Atlanta, 1992.

[5] Ružić, D., Improvement of thermal comfort in a passenger car by localized air distribution. Bulletin of Engineering Tome, IV, pp. 2067-3809, 2011.

[6] Zhang, H., Dai, L., Xu, G., Li, Y., Chen, W. \& Tao, W., Studies of air-flow and temperature fields inside a passenger compartment for improving thermal comfort and saving energy. Part I: Test/numerical model and validation. Applied Thermal Engineering, 29, pp. 2022-2027, 2009.

[7] Zhang, T., Li, P. \& Wang, S., A personal air distribution system with air terminals embedded in chair armrests on commercial airplanes. Building and Environment, 47(1), pp. 89-99, 2012.

[8] Zhang, T. \& Chen, Q., Novel air distribution systems for commercial aircraft cabins. Building and Environment, 42, pp. 1675-1684, 2007.

[9] Zhang, T., Yin, S. \& Wang, S., An under-aisle air distribution system facilitating humidification of commercial aircraft cabins. Building and Environment, 45, pp. 907-915, 2010.

[10] Kamar, H.M., Kamsah, N. \& Nor, A.M.M., Numerical analysis of air flow and temperature field in a passenger car compartment. The 4th International Meeting of Advances in Thermofluids, Malaysia, 1440, 2011.

[11] Singh, M. \& Bartaria, V.N., CFD analysis of modified car air distribution system by changing supply and return air vents. International Journal of Advance Engineering and Research Development, 2(4), 2015.

[12] Bahrami, M., Forced convection heat transfer, Faculty of Applied Science, School of Mechatronic Systems Engineering, Simon Fraser University, Canada. www.sfu.ca/ mbahrami/ENSC\%20388/Notes/Forced\%20Convection.pdf

[13] Zhang, T. \& Chen, Q., Comparison of different ventilation systems for commercial aircraft cabin. Proceedings of Indoor Air, IV, pp. 3205-3210, 2005.

[14] Fiser, J. \& Jícha, M., Impact of air distribution system on quality of ventilation in small aircraft cabin. Building and Environment, 69, pp. 171-182, 2013. 